\title{
A RARE CASE REPORT OF CONVERGENT STRABISMUS FIXUS
}

\section{H. R. Padmini ${ }^{1}$, Anyatama Chakravarty ${ }^{2}$}

\section{HOW TO CITE THIS ARTICLE:}

H. R. Padmini, Anyatama Chakravarty. "A Rare Case Report of Convergent Strabismus Fixus". Journal of Evolution of Medical and Dental Sciences 2014; Vol. 3, Issue 33, August 07; Page: 8949-8951,

DOI: $10.14260 /$ jemds/2014/3150

ABSTRACT: Convergent strabismus fixus is classified into congenital and acquired types; however, there are only a few detailed case reports of congenital convergent strabismus fixus. Surgical treatment of strabismus fixus by combined recession-resection is challenging. In our report, a rare case of congenital convergent type of strabismus fixus is described and its surgical management is discussed.

KEYWORDS: Convergent, Fixus, Extraocular, Fibrosis, Strabismus, Surgical correction.

INTRODUCTION: Strabismus fixus is a rare condition and usually is of convergent type in which one or both eyes are anchored in a position of extreme adduction. Convergent type strabismus fixus is considered to be a congenital disorder and a part of congenital extraocular muscle fibrosis syndrome. It has also been reported that progressive esotropia could develop into the acquired type of convergent strabismus fixus. ${ }^{1,2}$ Surgical treatment of strabismus fixus is challenging. Options for its correction range from conventional combined recession-resection surgery to innovative surgical procedures aiming to correct the deviated muscle paths.

CASE REPORT: Here we present the case of a fifty two years old woman who presented with marked inward turning of both eyes since childhood and gross diminution of vision causing great discomfort and disability as she was unable to look straight ahead. The patient also presented with bilateral senile immature cataract, causing further impairment in vision. She also had mental retardation and poor coordination since childhood as informed by her attendant, but no previous medical consultation details were provided.

Her visual acuity was counting finger $1 \mathrm{~m}$ in the right eye and perception of light in the left eye, not improving with pinhole. There was a very large bilateral convergent squint and both eyes were fixed in extreme adducted position with no possibility of extraocular movement. Fundoscopic examination and ultrasound biomicroscopy of the posterior segment revealed no significant abnormality.

The patient was taken up for surgical correction of the left eye under local anesthesia. Forced duction test preoperatively showed restriction in all directions and maximum in abduction. On exposure, the conjunctiva and tenon's capsule on the medial side of the left eye appeared thickened and fibrosed. The fleshy and thickened tendon of the medial rectus muscle showed an anomaly of insertion, being only $2.2 \mathrm{~mm}$ away from the limbus.

A medial rectus tenotomy and tenectomy with conjunctival and tenon's resection was performed to achieve correction. This was followed by manual small incision cataract surgery through a temporal section and a posterior chamber intraocular lens (IOL) was placed in position.

Post operatively, the squinting left eye showed some improvement in alignment and visual improvement of counting finger $2 \mathrm{~m}$. 
DISCUSSION: The pathogenesis of strabismus fixus remains poorly understood. Some authors believe it to be a part of extraocular muscle fibrosis syndrome which arises from dysfunction of oculomotor, trochlear and abducens nerve and the muscles they innervate causing incomitant strabismus with or without ptosis. 3,4

Surgical correction of strabismus fixus yields variable results. Combined recession-resection surgery yields good results for smaller deviations with mildly impaired motility, additional fixation techniques need to be applied once the horizontal muscle paths are deviated, and in extreme cases, a transposition procedure is required. ${ }^{5}$

CONCLUSION: In our patient, the clinical presentation goes in favour of the diagnosis of a congenital/genetic type of strabismus fixus rather than due to myopic myositis. It could also be a progressive esotropia developing into strabismus fixus. High myopic astigmatism causing poor vision may have accentuated/or caused esodeviation in early childhood which developed over several years into strabismus fixus.

Surgical treatment in our case was offered at the age of 52. If presented before, surgery should be offered early in cases with extreme degrees of deviation. However a combined attempt of squint correction and cataract extraction with IOL implantation in this case achieved some desired visual improvement.

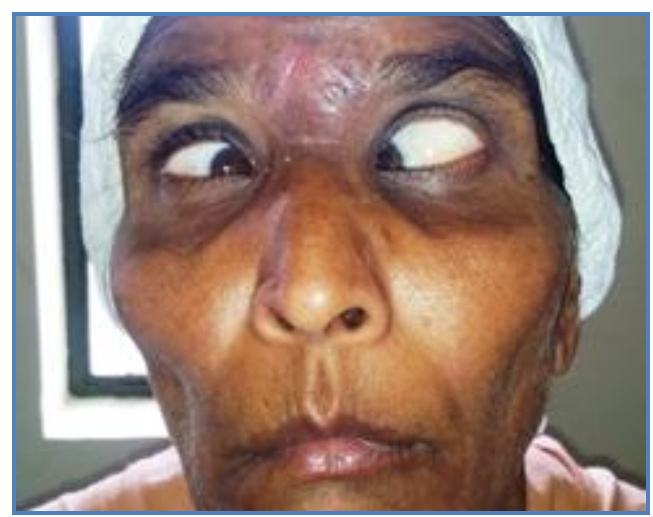

Pre-operative

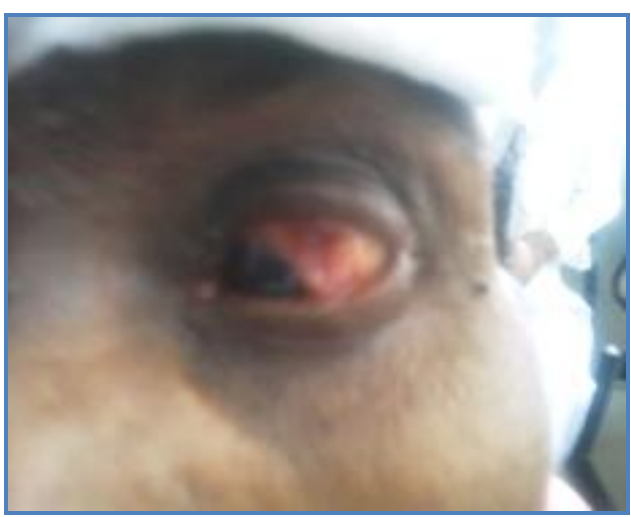

Post-operative

\section{REFERENCES:}

1. Villasecca A. Strabismus fixus. Am J Ohthalmol 1959; 48: 51.

2. Hayashi T, Maruo T. Acquired progressive esotropia and acquired strabismus fixus. Nippon Ganka Gakkai Zasshi 1999; 103: 604-11.

3. Martinez L. A case of fixed strabismus. Am J Ophthal mol 1948; 31: 80.

4. Hugonnier R, Clayette-Hugonnier S, Veronneau-Troutman S. Strabismus, Heterophoria, Ocular motor paralysis, p:205. CV Mosby, St. Louis. 1969

5. Aebli R. Retraction syndrome, Arch Ophthalmol.1933; 10:602=610. 


\section{CASE REPORT}

\section{AUTHORS:}

1. H. R. Padmini

2. Anyatama Chakravarty

\section{PARTICULARS OF CONTRIBUTORS:}

1. Professor and HOD, Department of Ophthalmology, Adi Chunchanagiri Institute of Medical Sciences (AIMS).

2. Post Graduate Resident, Department of Ophthalmology, Adi Chunchanagiri Institute of Medical Sciences (AIMS).

\section{NAME ADDRESS EMAIL ID OF THE} CORRESPONDING AUTHOR:

Dr. H. R. Padmini,

Department of Ophthalmology,

AIMS, B. G. Nagara-571448,

Nagamangala Taluk,

Karnataka.

Email: drhrpsai@yahoo.com

Date of Submission: 10/07/2014.

Date of Peer Review: 11/07/2014.

Date of Acceptance: 25/07/2014.

Date of Publishing: 07/08/2014. 